\title{
ANTONIN ARTAUD EN MÉXICO. LUCHA POR LA HEGEMONÍA \\ CULTURAL, ENTRE LA RAZÓN Y LA LOCURA
}

Antonin Artaud in Mexico. Struggle for Cultural Hegemony, between Reason and Madness

Carlos A. Garduño Comparán, Universidad Autónoma del Estado de México, México Correo electrónico: eidoshumanidades1@gmail.com

Recibido: 02/08/2019

Aceptado: 25/06/2020

Resumen: En este texto se discute el problema de los efectos de la fundamentación racional del pensamiento sobre la identidad y la cultura, así como la lucha por la hegemonía que se deriva de las condiciones que la razón impone, con el fin de cuestionar los límites entre pensamiento, cultura y razón. Para ello, se analiza el caso particular del viaje que Antonin Artaud realizó en 1936 a México, a la luz de la discusión teórica desarrollada por Michel Foucault, Jacques Derrida y Slavoj Žižek acerca de las relaciones entre pensamiento y locura.

Palabras clave: Antonin Artaud, Locura, Cogito, Identidad, Hegemonía, Michel Foucault, Jacques Derrida, Slavoj Žižek.

Abstract: This text discusses the problem of the effects of rational foundation thinking on identity and culture, as well as the struggle for hegemony that derives from the conditions that reason imposes, in order to question the boundaries between thought, culture and reason. In order to do so, I analyze the particular case of Antonin Artaud's trip to Mexico in 1936, through the concepts of the discussion developed by Michel Foucault, Jacques Derrida and Slavoj Žižek on the relationships between thought and madness.

Keywords: Antonin Artaud, Madness, Cogito, Identity, Hegemony, Michel Foucault, Jacques Derrida, Slavoj Žižek. 


\section{Introducción}

A lo largo de la historia del pensamiento éste ha intentado definir su propia validez, determinando lo que, como parte de sí mismo, establezca un fundamento confiable que garantice o al menos refiera a la posibilidad de acceder, conocer o comprender la realidad. La determinación del fundamento, sin embargo, genera una escisión del sujeto pensante, pues no sólo postula lo que en el orden del pensamiento es confiable, sino, en ese mismo acto, lo que no es confiable. El pensamiento, pues, parece desarrollarse sólo a través de oposiciones, donde uno de sus elementos designa lo válido y el otro lo que lo contradice. Ahora bien, en este texto, más que evaluar la validez de estos intentos metafísicos, interesa discutir la forma en que la fundamentación del pensamiento incide en el desarrollo de la identidad y la cultura, y cómo los individuos, a su vez, luchan por afirmar su identidad y cultura frente a la racionalidad impuesta.

Como primera hipótesis, podemos suponer que, cuando se introduce una distinción metafísica, no simplemente se modifica un ámbito particular de la cultura aquél en que se lleva a cabo la especulación filosófica-, sino que, paulatinamente, mientras se van asimilando y aceptando los enunciados fundamentales, el resto de la cultura se modifica en consecuencia. En esta perspectiva, pensamiento y cultura comparten una estructura que funciona como sistema de razonamiento. Al postular un principio axiomático ('el ser es y el no ser no es', A=A, etc.), el resto del sistema se acomoda a él en estricta coherencia, descartando como una amenaza a su consistencia lo que no se ajusta a la lógica impuesta. Cualquier análisis que se siga de ello no podría más que partir de la definición de la identidad que el mismo sistema posibilita, para dilucidar el lugar que al resto de los elementos corresponde, lo cual equivale a determinar lo que no puede ser parte de una cultura y no puede ser pensado más que como su exclusión.

Como segunda hipótesis, podemos suponer que los enunciados fundamentales no tienen la capacidad de totalizar la dinámica cultural como un sistema coherente y homogéneo, sino que la dinámica se sigue desarrollando más allá de los límites de la identidad, promoviendo modificaciones que podrían alterar el orden que la razón impone. Mientras en la primera hipótesis se impone un criterio de racionalidad sobre todo el ámbito cultural, dejando en sus márgenes aquello que, por su incapacidad de servirse de 
la razón, no puede ser parte de la dinámica cultural, en la segunda incluso quienes no están a la altura de los principios siguen interactuando culturalmente, produciendo manifestaciones que en su oposición podrían modificar los sistemas. De ser esto posible, el ámbito de pensamiento en el que se desarrolla la cultura no podría igualarse al de la razón, dejando en suspenso, por tanto, la posible definición del pensamiento. Lo que en ambas hipótesis se cuestiona son los límites del desarrollo de la razón, el pensamiento y la identidad.

En este texto, propongo explorar la conflictiva relación entre estos términos a través de un caso particular: el pensamiento y la producción artística de Antonin Artaud, específicamente, durante su viaje a México, en el que emprendió una peculiar búsqueda de las raíces profundas de su cultura. Y, para intentar conceptualizarlo, me basaré en los acercamientos teóricos de Michel Foucault, Jacques Derrida y Slavoj Žižek, en los que se discute, por un lado, la obra y la figura misma de Artaud y, por otro, como horizonte de discusión fundamental, la relación entre pensamiento y locura.

La pertinencia de discutir las relaciones entre pensamiento y locura como base de la compresión del desarrollo de una dinámica cultural radica en que la locura es la categoría con la que, sobre todo desde el horizonte de la racionalidad moderna, se designa su no-ser, lo que pasa con el pensamiento cuando no puede hacer uso de la razón, tal como los criterios fundamentales de su cultura lo han establecido. Al respecto, el caso de Artaud es interesante, por dos cuestiones: porque su pensamiento funciona en los márgenes de la razón; y porque ello no le impidió ser productivo, cuestionar — hasta rechazar - los límites de la identidad cultural europea, poniendo en juego su propia identidad, explorar la identidad de otras culturas, como la mexicana, en su irreductible diferencia y hasta afectar los fundamentos mismos de la cultura europea con sus propuestas, producciones y pensamientos. ${ }^{1}$

\footnotetext{
${ }^{1}$ Para un acercamiento general al pensamiento de Artaud, expresado en las categorías que interesan en este trabajo (relación entre espíritu y cuerpo, relaciones entre cultura y metafísica, la crueldad del arte como respuesta a lo dado en el mundo), consúltese el artículo de Paola Andrea López, "El heroísmo de Antonin Artaud", Praxis Filosófica, núm. 49 (julio-diciembre 2019): 151-170. doi: 10.25100/pfilosofica.v0i49.8246. Por otro lado, cabe destacar que aquí no pretendemos explorar exhaustivamente el pensamiento, vida u obra de Artaud, sino tan sólo utilizar su viaje a México como ilustración de la discusión filosófica sobre los las relaciones entre racionalidad, cultura e identidad, dada la relevancia de Artaud en la reflexión contemporánea, como figura que pone en cuestión los límites del pensamiento (ver siguiente nota).
} 
Así pues, a continuación, abordaré los elementos teóricos que me permitirán analizar y discutir el viaje de Artaud a México a partir de los propios textos que él iba produciendo durante su experiencia. Los elementos teóricos en cuestión son los siguientes: el análisis de Michel Foucault, en su Historia de la locura, de los distintos discursos que, durante la modernidad, establecieron una relación específica entre razón y locura, la cual se modificó hasta posibilitar el surgimiento de la figura de Artaud; la discusión que Jacques Derrida establece con Foucault, en La escritura y la diferencia, sobre su proyecto de realizar la Historia de la locura y, en particular, sobre su interpretación del Cogito cartesiano; la deconstrucción que Derrida realiza, en el mismo libro, del discurso de Artaud; el análisis que Slavoj Žižek, en Menos que nada, hace de la discusión entre Foucault y Derrida, y su propia aportación. ${ }^{2}$

\section{Cogito y locura}

En Ortodoxia, G. K. Chesterton dedica el primer capítulo de su polémica contra los materialistas, a los "maniáticos". Su argumento interesa porque, en contra del sentido común, no intenta definir la locura por su oposición a la razón, sino en los siguientes términos:

La imaginación no provoca la locura. Para ser exacto, lo que fomenta la locura es la razón. Los poetas no enloquecen; los jugadores de ajedrez sí. Los matemáticos y los cajeros, se vuelven locos; pero rara vez enloquecen los artistas que crean. Como podrá verse, en ninguna forma ataco la lógica: digo solamente que el peligro de la locura reside en la lógica; no en la imaginación. ${ }^{3}$

\footnotetext{
${ }^{2}$ Otros autores relevantes para la discusión filosófica han abordado a profundidad la obra y figura de Artaud, siendo incluso influenciados en su propio pensamiento por él. Camille Dumoulié, en Nietzsche y Artaud. Por una ética de la crueldad (México: Siglo XXI, 1996), mostró la posibilidad de una ética más allá de los límites de la racionalidad tradicional. Julia Kristeva, en su ensayo "Le sujet en procès", en Polylogue (Paris: Seuil, 1977), explora los experimentos semióticos de Artaud y en función de ellos cuestiona los límites del pensamiento y el lenguaje. Gilles Deleuze, en su libro sobre Francis Bacon Francis Bacon La logique de la sensation (París: Seuil, 2002), particularmente en los capítulos 6 y 7, sobre la sensación en la pintura y la histeria - refiere a Artaud como influencia de una estética que no se apoya en la noción de representación. Por otro lado, junto a Félix Guattari, en "¿Cómo hacerse un cuerpo sin órganos?", en Mil mesetas. Capitalismo y esquizofrenia (Valencia: Pre-Textos, 2002), retoma de Artaud la noción de cuerpo sin órganos, como uno de los pilares de su propia metafísica. En este texto, sin embargo, no profundizaremos en todos estos abordajes porque lo que se propone es enfocarnos sólo en la relación entre pensamiento y locura como problema metafísico, pero también cultural y político —en el sentido de lucha por la hegemonía-. En ello baso la elección de los autores y textos a discutir.

${ }^{3}$ G. K. Chesterton, Ortodoxia (México: Porrúa, 1998), 10.
} 
La razón misma, asegura, y no la imaginación, provocan la locura. El loco, en esta visión, es el que reduce la realidad a los límites de lo que puede razonar. Pero, ¿qué sucede en esos conocidos casos de artistas que bordearon la locura, como Poe, Van Gogh o el mismo Artaud? Chesterton nos dice que "Poe, por ejemplo, fue realmente morboso; no porque fue poético, sino porque fue esencialmente analítico. Aun el ajedrez era demasiado poético para él; le desagradaba porque había demasiados caballeros y castillos, como en un poema". ¿Quiere esto decir que el matemático y el metafísico, cuyo pensamiento pretende funcionar en el ámbito de la razón pura, ${ }^{5}$ si permanecen exclusivamente en él, son la definición misma de la locura? ¿Que la locura de Poe consistió en racionalizar en exceso su producción poética? ${ }^{6}$ De ser así, el pensamiento que se define racionalmente a sí mismo, y que en esa pretensión intenta superar o evitar la locura, es una suprema ironía.

En su Historia de la locura, Foucault parece ilustrar justo dicho intento, a través de la figura de René Descartes. El argumento de Foucault es que la razón moderna se funda en la segregación de la locura del ámbito del pensamiento, inaugurando así una época en la que sólo se puede relacionar con ella internándola bajo la justificación de un discurso psiquiátrico. Para ilustrarlo, recurre, entre otros motivos, a la segunda de las Meditaciones metafísicas de Descartes, ${ }^{7}$ en la que a su parecer éste sólo menciona la locura para excluirla de cualquier consideración formal en el ámbito de lo que puede ser pensado.

En el momento en que la duda lo enfrentaba a grandes riesgos, Descartes tomaba conciencia de que no podía estar loco - aunque reconoció aún durante mucho tiempo que todas las potencias del mal y hasta un genio maligno rondaban alrededor de su pensamiento-; pero en tanto que filósofo, y teniendo el

\footnotetext{
${ }^{4}$ Ibid., 11.

${ }^{5} \mathrm{Al}$ respecto, no habría que olvidar que Kant, precisamente en la Crítica de la razón pura, establece que las matemáticas son conocimiento valido por consistir en juicios sintéticos a priori, es decir, son capaces de vincularse sintéticamente con las condiciones formales de la intuición y referir por ello a experiencias posibles o actuales. La metafísica, en cambio, aunque puede ser fundamento de la moral, lo hace, como establece en la Fundamentación de la metafísica de las costumbres, de una manera pura. ¿Querrá esto decir que una moral rígida e intransigente, y no un razonamiento matemático riguroso, es la forma de locura por excelencia?

${ }^{6}$ Al respecto, consúltese su Filosofía de la composición, en la que explica el método que siguió para concebir su célebre poema "El cuervo".

${ }^{7}$ Desde las primeras páginas del segundo capítulo de la primera parte de La historia de la locura, de título "El gran encierro", y con menciones esporádicas a lo largo de la obra.
} 
propósito resuelto de emprender el camino de la duda, él no podía ser "uno de esos insensatos". 8

La duda metódica llevó a Descartes a realizar especulaciones excéntricas e insensatas, como las de un loco, pero su método en realidad fue pensado para superarlas; para distinguirse y afirmarse como un ser racional. Esto, en suma, es lo que, desde su fundamentación metafísica, caracteriza para Foucault a la razón moderna.

En contra de este impulso cartesiano, sin embargo, Foucault muestra cómo desde el arte y la literatura se va realizando una reconsideración del loco. Uno de sus ejemplos es El sobrino de Rameau, de Denis Diderot: "El sobrino de Rameau sabe bien $-\mathrm{y}$ es lo que lo hace obstinarse en sus huidizas certidumbres - que está loco".9 Descartes sabe bien —o eso pareciera terminar afirmando- que no está loco, mientras que el sobrino de Rameau sabe bien lo contrario. ¿Cómo llegó a tal certeza? "Está loco porque se le dice que lo está y se lo trata como tal". ${ }^{10}$ Entre Descartes y el sobrino de Rameau tenemos una oposición entre autonomía y heteronomía: ${ }^{11}$ uno sabe lo que es porque se pensó a sí mismo y el otro sabe lo que es porque otro se le dijo; uno es el epítome de la razón ilustrada, el otro, la locura que rechaza. Y, sin embargo, para Foucault, en éste ya se empieza a prefigurar la separación de la locura y la sinrazón, porque lo que muestra Diderot es que, aunque el sobrino de Rameau no está a la altura del ideal cultural, está ahí con los ilustrados como su bufón. La sociedad ilustrada, con sus expectativas y sus miradas, es la que constituye, como su bufón, al loco. Por ello, Foucault concluye que la "razón no puede dar fe de la locura sin comprometerse ella misma en las relaciones de poseer". ${ }^{12}$ Que los ilustrados, para afirmarse en su razón, requieran sus bufones de los cuales distinguirse, equivale para Foucault al hecho de que "la locura no es, nunca, más que aquello que la razón puede poseer de sí misma". ${ }^{3} \mathrm{Y}$, gracias a obras como la de Diderot, podemos darnos cuenta de que "la razón se enajena

\footnotetext{
${ }^{8}$ Michel Foucault, Historia de la locura en la época clásica II (México: Fondo de Cultura Económica, 1976), 9.

${ }^{9}$ Ibidem.

${ }^{10}$ Ibidem.

${ }^{11}$ La oposición entre autonomía y heteronomía en los procesos de pensamiento y habla, son fundamentales en el pensamiento de Foucault sobre el poder, a lo largo de toda su obra. Como referencia, consúltese su diálogo con Deleuze "Los intelectuales y el poder" y su seminario El gobierno de sí y de los otros.

${ }^{12}$ Foucault, Historia de la locura, 12.

${ }^{13}$ Ibidem.
} 
en el movimiento mismo en que toma posesión de la sinrazón". ${ }^{14}$ Diderot, tratándose de apropiar del loco, enajena su propia obra, la cual, a partir de entonces, ya no puede ser un producto puro de la razón ilustrada.

Desde ese momento, el arte ha explorado esa figura, extraña y familiar, exterior, pero propia y hasta íntima; ${ }^{15}$ inusitada conjunción de los extremos, que oscila entre "el aniquilamiento total de una conciencia" y "la suprema glorificación de una conciencia soberana". ${ }^{16}$ En referencia a la dialéctica hegeliana del amo y el esclavo, el loco parece ocupar, indistintamente, ambos puntos de oposición. ¿Querrá esto decir que los límites del pensamiento en los que la razón se constituye, son puntos de locura?

Cuando se piensa, en cambio, que el proyecto de Descartes consistía en soportar la duda de manera provisional hasta la aparición de lo verdadero en la realidad de la idea evidente, puede verse bien que el no-cartesianismo del pensamiento moderno, en lo que puede tener de decisivo, no comienza con una discusión sobre las ideas innatas o la acusación del argumento ontológico, sino, en cambio, en este texto del sobrino de Rameau, en esta existencia que él designa en una inversión que sólo podría ser entendida en la época de Hölderlin y de Hegel. ${ }^{17}$

El sobrino de Rameau es la expresión literaria de una inversión, análoga a las de la dialéctica hegeliana, en que se pone en cuestión, en el orden mismo del pensamiento, la jerarquía de la razón sobre la locura, haciendo posible, en consecuencia, no sólo que la locura sea poseída por la razón, sino que la razón sea interrogada desde la locura. Con ello, se muestra que, por un lado, Descartes representa un momento de la historia del pensamiento en el que se impone la pretensión de reducirlo a sus principios racionales, para establecer una relación sistemática con la realidad, que, al ser asimilada socialmente a través de diversas prácticas que la asumen como su método, va dando forma a una cultura propiamente moderna, que tiene como consecuencia la exclusión de la locura, la cual, en ese marco, sólo se concebirá como carencia de pensamiento. Por otro lado, exploraciones artísticas y literarias como la de Diderot posibilitaron la representación de aquello que fue excluido metafísicamente y su regreso al ámbito de la cultura,

\footnotetext{
${ }^{14}$ Ibidem.

15 Todas estas, interesantemente, son cualidades de "Lo ominoso", tal como Sigmund Freud las desarrolló en su ensayo sobre El hombre de arena de E. T. A Hoffmann.

${ }^{16}$ Foucault, Historia de la locura, 16.

17 Ibid., 16-17.
} 


\section{enn-claves}

permitiendo a su vez nuevas especulaciones filosóficas, como la de Hegel, acerca de los límites del pensamiento que no pueden establecerse sólo a partir de la razón, sino siempre en relación a su opuesto, frente al cual podría enseñorearse o perderse. Todo ese proceso, según Foucault, dio paso a otra forma de cultura: "La risa del sobrino de Rameau prefigura y reduce todo el movimiento de la antropología del siglo XIX". ${ }^{18}$ Una nueva concepción del hombre que posibilitará obras de célebres locos, en el arte y el pensamiento, como las de Nietzsche o Artaud.

Estos nuevos artistas y pensadores que, bajo los presupuestos cartesianos serían locos, "en el porvenir serán las rejas indispensables para hacer que resulten legibles nosotros y nuestra cultura". ${ }^{19}$ El veredicto de Foucault es que, en una perspectiva histórica, más allá de lo que tuvo que sufrir en su época, “Artaud pertenecerá al suelo de nuestro idioma, y no a su ruptura; las neurosis a las formas constitutivas (y no a las desviaciones) de nuestra sociedad". ${ }^{20}$ Aunque en su momento Artaud ocupó el lugar de la negatividad del proceso dialéctico del pensamiento, en un futuro (quizá nuestro presente), sus aportaciones pueden ser reconocidas y ser parte de nuestras costumbres.

¿Quiere esto decir que el Cogito cartesiano no es más que un producto históricocultural que de hecho ya fue superado, o hay algo del pensamiento de Descartes que permanece? Para Foucault, lo que permanece "es la relación del hombre con sus fantasmas, con su imposible, con su dolor sin cuerpo, con la cáscara de su noche". ${ }^{21}$ No el Cogito, tal como Foucault lo entiende, sino "el vínculo de una cultura con aquello mismo que ella excluye, y más precisamente el vínculo de la nuestra con esta verdad de sí mismo, lejana e inversa, que descubre y recubre en la locura". ${ }^{22}$ La locura, en la exclusión, y su vínculo con la cultura, es lo que permanece; Descartes, su metafísica y, con ello, la razón moderna, son dejados atrás. Pero, ¿no nos decía Chesterton que las pretensiones de la razón moderna eran la locura misma?

Foucault caracteriza la locura como el silencio, la ausencia de obra, el lado excluido y que permanece en la oscuridad de la cultura, lo que no logra acceso positivo al idioma: "una experiencia, en que hay algo de nuestro pensamiento; su

\footnotetext{
${ }^{18}$ Ibid., 20.

${ }^{19}$ Ibid., 328.

${ }^{20}$ Ibidem.

${ }^{21}$ Ibid., 329

${ }^{22}$ Ibid., 330.
} 
inmanencia, ya visible, pero absolutamente vacía, aún no puede nombrarse". ${ }^{23}$ De acuerdo con esto, podríamos decir que Artaud, en virtud de su experiencia de la locura, realizó una obra en la que, aunque no es nombrada como tal, puede seguirse en su obra como el trasfondo oscuro, que permanece en silencio y que no puede hablar por sí mismo. ${ }^{24}$ ¿Qué pasaría, sin embargo, si la locura misma hablara, no sólo en la obra, sino a través de la razón? ¿No sería la voz del Cogito lo que revolucionaría el ámbito cultural, como el loco que le permite al sujeto normal cobrar consciencia de la realidad de su pensamiento?

Ésta es la hipótesis que Derrida suscribe en la discusión que establece con Foucault acerca de su interpretación del Cogito. Para Derrida, la experiencia del Cogito no es exclusiva de un momento histórico-cultural como afirma Foucault, y además no es ajena a la locura, sino que ésta se constituye desde su interior $y$, por ello, no puede ser excluida. Así pues, para Derrida, en cualquier momento podríamos reconocer la experiencia del Cogito constituyéndose en relación a la locura. No es sólo que la razón, independientemente del momento histórico, impondrá su orden, sino que la razón, en su momento de reflexión más radical, encontrará en sí la locura. ${ }^{25}$

En específico, Derrida discute la hipótesis de Foucault de que Descartes decide romper el diálogo entre razón y locura. Para Derrida, hay un error de juicio: “Al querer escribir la historia de la decisión, de la partición, de la diferencia, se corre el riesgo de constituir la división en acontecimiento o en estructura que sobreviene a la unidad de una presencia originaria; y de confirmar así la metafísica en su operación fundamental". ${ }^{26}$ El problema, piensa Derrida, es que Foucault, más allá de los efectos al interior del pensamiento y el lenguaje, supone la presencia originaria de la razón y la locura, lo cual le impide percibir que su diferencia en realidad se constituye en el

\footnotetext{
${ }^{23}$ Ibid., 229-240.

${ }^{24}$ Anne Bouillon analiza esta experiencia por la que pasó Artaud, durante sus viajes a México e Irlanda, y junto con Deleuze, cuestiona si al traspasar los límites del sentido es posible encontrar nuevas posibilidades para el pensamiento radical. Al respecto, es también pertinente el artículo de Jon Shaw, "The Life of an Idiot: Artaud and the Dogmatic Image of Thought after Deleuze". Anne Bouillon, Gilles Deleuze et Antonin Artaud. L'impossibilité de penser (París: L'Harmmattan, 2016).

${ }^{25}$ Para un análisis de esta cuestión en específico, consúltese el artículo de Wendy Cealey Harrison, "Madness and Historicity: Foucault and Derrida, Artaud and Descartes". History of the Human Sciences, 20, núm. 4 (2007): 79-105. doi.org/10.1177/0952695107082492.

${ }^{26}$ Jacques Derrida, "Cogito e historia de la locura", en La escritura y la diferencia (Barcelona: Anthropos Editorial, 2012), 60.
} 
orden del lenguaje como parte de la función de ordenamiento y generación de sentido que lo caracteriza. $^{27}$

En contra, según Derrida, Descartes no comete el error de afirmar la presencia de la locura para después excluirla, sino que la admite como posibilidad en diferentes expresiones del pensamiento, desde la ilusión sensible, pasando por el sueño, hasta la radicalización de la duda con el genio maligno. "Lo que hay que retener aquí es que, desde este punto de vista, el durmiente, o el soñador, está más loco que el loco". ${ }^{28}$ La locura, entonces, no es rechazada como una anormalidad, sino que es considerada una experiencia que acompaña al pensamiento en sus manifestaciones cotidianas.

Ahora bien, para Derrida, la reflexión de Descartes es tan radical que no sólo no excluye la locura, sino que, en su esfuerzo de afianzar el Cogito, convoca la posibilidad de una locura total con la hipótesis del genio maligno: "una locura que introducirá la subversión en el campo de las ideas claras y distintas, en el dominio de las verdades matemáticas que escapan a la duda natural". ${ }^{29}$ Bajo esta interpretación, ninguna idea estaría a salvo de la locura, y ésta, "que hace un momento era separad[a] bajo el nombre de extravagancia es acogid[a] ahora en la más esencial interioridad del pensamiento". 30

Aunque el lenguaje genere sentido oponiéndose a la locura, ésta no queda al margen, sino que es su límite y su recurso. La locura no se evoca como algo externo, sino "en la dimensión de la posibilidad y en el lenguaje de la ficción o en la ficción del lenguaje". ${ }^{31}$ Es, pues, como un medio de afirmación propio de toda forma de lenguaje, "incluso del de los más locos aparentemente". ${ }^{32}$ Es decir, para poder encontrar la seguridad del Cogito, Descartes tuvo que reconocer como posibilidades íntimas de su propio pensamiento las múltiples formas de la locura. Lo que descubrió con ello, según Derrida, fue que el Cogito es válido incluso si estoy loco, y que la locura no es más que un caso del pensamiento. Un caso particular que, lejos de ser excluido, tiene la importante función de ser "el punto en el que se enraíza el proyecto

\footnotetext{
${ }^{27}$ En este sentido, los análisis semióticos de Kristeva sobre Artaud dan cuenta de los procesos lingüísticos involucrados en lo que puede percibirse como locura, pero también como fuente de creación. Kristeva, "Le sujet en procès".

${ }^{28}$ Derrida, "Cogito e historia de la locura", 72.

${ }^{29}$ Ibid., 75.

${ }^{30}$ Ibidem.

${ }^{31}$ Ibid., 77.

${ }^{32}$ Ibidem.
} 
de pensar la totalidad", 33 como un exceso o "hipérbole demoniaca", ${ }^{34}$ una violencia propia del pensamiento, de la cual Descartes da cuenta.

Sólo por ello es que Descartes puede asegurar que no está loco: "hace falta no estar loco de hecho para reflejarlo, retenerlo, comunicarlo, comunicar su sentido". ${ }^{35}$ Si la locura es parte constitutiva del pensamiento, como su exceso y su violencia, la cordura no es la exclusión de la locura, sino el poder dar cuenta de ella como lo más íntimo de la propia experiencia del pensamiento. Por ello, las Meditaciones son locura y cordura a la vez: "el Cogito es obra desde el momento en que se reafirma en su decir. Pero es locura antes de la obra". ${ }^{36}$ La cordura se logra con el reconocimiento de la locura que constituye el pensamiento propio, lo cual posibilita la obra. La locura, así, es la posibilidad misma de la obra que, antes de reconocerse a sí misma, es ausencia e incluso impotencia de obra, sentido y razón. "Y la filosofía es, quizás, esa seguridad que se adquiere en la mayor proximidad de la locura contra la angustia de estar loco". 37 Desde este punto vista, el pensamiento metafísico no simplemente postula principios que excluyen lo que no esté a la altura de su racionalidad, sino que constituye su racionalidad en el reconocimiento de que el pensamiento es también fundamentalmente lo que se opone a la razón y lo que de hecho la posibilita, como el exceso que le da sentido al orden. ${ }^{38}$

Justo en este punto de exceso, Žižek se concentra para mostrar, a partir de la discusión entre Foucault y Derrida, cómo la locura supone de hecho la entrada al orden simbólico, lo cual en retrospectiva es interpretado como "la imposición de un orden simbólico al caos de lo Real". ${ }^{39}$ Desde esta perspectiva, la entrada al orden es un exceso violento, un caos, una locura, que funda el pensamiento mismo y su racionalidad, el cual, una vez establecido, se justifica como el orden que limita y controla su propio origen, representado desde entonces como lo real exterior al lenguaje.

\footnotetext{
${ }^{33}$ Ibid., 79.

${ }^{34}$ Ibid., 80.

${ }^{35}$ Ibid., 81-82.

${ }^{36}$ Ibid., 84.

37 Ibid., 85.

${ }^{38}$ Este exceso parece acompañar la reflexión filosófica, desde la locura divina del Fedro de Platón, hasta la negatividad hegeliana. Al respecto, en la segunda parte de De la gramatología, en su análisis del ensayo de Rousseau sobre el origen de las lenguas, Derrida muestra cómo tal exceso suele ser representado como un suplemento que distorsiona la presencia originaria.

39 Slavoj Žižek, "El cogito en la historia de la locura", en Menos que nada. Hegel y la sombra del materialismo dialéctico (Madrid: Akal, 2015), 367.
} 
En consonancia con Derrida, para Žižek, la filosofía trascendental, el Cogito, la reflexión que posibilita la autoconsciencia, inscribe la locura en el pensamiento, superando su falsa apariencia de exterioridad, lo cual implica que reconoce la locura como algo ex-timo. ${ }^{40}$

Foucault, en su respuesta a Derrida, le reprocha su tesis de que "no hay afuera del texto", ${ }^{41}$ porque le impide reconocer los efectos de exclusión del discurso de Descartes. Žižek, más cercano a Derrida, rechaza la idea de oponer el orden simbólico a un mundo exterior por el hecho de que lo simbólico es la mediación que de hecho posibilita la percepción de lo exterior y porque su orden posibilita la experiencia misma de la locura. Sólo los humanos, por vivir en un mundo simbólico, pueden estar locos. Y la razón se constituye y adquiere sentido sólo en relación a esa locura de quien habita en lo simbólico. ${ }^{42}$

Esta compenetración de razón y locura, como constitutiva del orden, implica que éste no pueda concebirse nunca como totalmente consistente, siendo tal pretensión una fantasía paranoide. El paranoico, a través de sus fantasías, trata de defenderse de la locura evadiendo el hecho de que el orden es inconsistente; intenta llenar sus vacíos con narraciones sobre un orden o un dios que traman el destino de las cosas. Podríamos decir que el pensamiento de Descartes es, por un lado, el reconocimiento radical de la locura como constitutiva del pensamiento y, por otro, su evasión paranoica al argumentar la existencia de Dios como garantía de la existencia del mundo exterior. ${ }^{43}$

En todo caso, el punto de Žižek es que todos estos son fenómenos posibilitados por el lenguaje como médium del pensamiento, que genera hábitos como formas de

\footnotetext{
${ }^{40}$ Término con el que Jacques Lacan refiere a lo que en un momento es reconocido por el pensamiento como externo y opuesto, pero que, en otro, debe ser reconocido como íntimo. Por supuesto, esto recuerda a lo siniestro freudiano (ver nota 15), pero Lacan lo conceptualiza, en su seminario sobre La angustia, bajo la denominación de 'objeto a', precisamente como el exceso que, en retrospectiva, en su asimilación por el aparato psíquico, funciona como la causa de deseo en relación a la cual el sujeto experimenta las diversas afecciones que definen su identidad.

${ }^{41}$ Foucault, "Mi cuerpo, ese papel, ese fuego", en La historia, 371.

${ }^{42}$ El esfuerzo por pensar lo que está más allá del orden simbólico corresponde a lo que Lacan denominó antifilosofia, noción que forma parte de las discusiones fundamentales de Alain Badiou. Al respecto, consúltese el artículo "¿Qué es antifilosofía?” de Alejandro Cavallazzi, “¿Qué es antifilosofía? Una consideración según Lacan, Badiou y la filosofía edificante de Rorty". Revista interdisciplinaria de $\begin{array}{lllllll}\text { Filosofía } & y & \text { Psicología, } & \text { 14, } & \text { núm. } & 2 & \text { (2019). }\end{array}$ https://www.revistalimite.cl/index.php/limite/article/view/108/109. Sobre la opinión de Žižek al respecto, consúltese el último apartado del capítulo XII de Menos que nada.

${ }^{43}$ En la tercera meditación.
} 


\section{enn-claves}

internalización, las cuales no son más que simbolizaciones que constituyen nuestros mundos de vida, que se manifiestan en diversas realidades culturales. Con ello, en un sentido hegeliano, aunque estas culturas tienen tan sólo una existencia virtual, deben ser realizadas como realidades efectivas en nuestras relaciones y ejercer una influencia activa sobre la manera en que percibimos y convivimos.

En esa percepción y convivencia, estructuradas simbólicamente, para Žižek, el loco es el que "quiere 'vivir' - reproducir en la realidad efectiva - el orden conceptual, actuar como si la locura también precediera efectivamente a la normalidad" ${ }^{44} \mathrm{El}$ loco es el que cree que existe una realidad efectiva que se distingue netamente de la locura y que es independiente de su estatuto simbólico; que cree que puede vivir y reproducir en sus circunstancias concretas el orden conceptual en cuanto tal, porque no tiene conciencia de su carácter simbólico y virtual, lo cual lo vuelve incapaz de fingir y disimular, de asumir roles y de modificar su relación con el contexto dependiendo de las exigencias sociales y culturales. Moverse eficazmente en el orden simbólico y no naufragar en la locura, siempre latente, implicaría aceptar que no hay una referencia final y real que determine la identidad del sujeto, y que no es posible la estabilización y la reconciliación de las relaciones entre lo particular y lo universal, lo cual implica que la autoobjetivación del sujeto es imposible.

Y esto nos lleva de vuelta a la locura: su definición más sucinta es la de una armonía directa entre la universalidad y sus accidentes, una cancelación de la fractura que separa a las dos; para el loco, el objeto - que es su representante imposible dentro de la realidad objetual_ _ pierde su carácter virtual y se hace una parte plena e integral de aquella realidad. ${ }^{45}$

El loco cree que lo que percibe es real independientemente de su mediación simbólica y de su contexto socio-cultural; el que, por carecer de tal conciencia, es incapaz de interpretar adecuadamente cada situación. En contra, "un hábito no es una identificación directa con alguna característica positiva, sino una identificación con una disposición, con una virtualidad". ${ }^{46}$ El loco, pues, es incapaz de generar hábitos eficazmente; el que fracasa en el intento de adaptarse al orden a través de hábitos reconocidos en contextos

${ }^{44}$ Žižek, "El Cogito en la historia de la locura", en Menos que nada, 388.

${ }^{45}$ Ibid., 397.

${ }^{46}$ Ibid., 398. 


\section{en-claves}

específicos. Y, sin embargo, su incapacidad no es simplemente una debilidad, una falta de razón o una torpeza, sino el resultado de una lucha -lo cual vuelve relevante la perspectiva de Foucault-: "El hábito es el resultado de una lucha por la hegemonía: es un accidente elevado a una 'esencia', a la necesidad universal, un accidente destinado a llenar su lugar vacío". ${ }^{47}$ La lucha en la que el loco sale derrotado, es una que entabla con su contexto por afianzar su identidad a través de hábitos que le permitan llenar el lugar vacio dentro de la estructura, en un intento de estabilizar su identidad. En su lucha, busca convertirse en un agente hegemónico haciendo valer algo particular y contingente como si fuera necesario y universal. Y su derrota consiste precisamente en creer en la necesidad y universalidad de lo que tan sólo es contingente y particular, sin ser reconocido en ciertas circunstancias socio-culturales.

En suma, tras nuestro repaso de las relaciones entre pensamiento y locura en Foucault, Derrida y Žižek, podemos destacar lo siguiente:

- En un primer acercamiento, la razón, particularmente la ilustrada, parece afianzarse al distinguirse de la locura, lo cual tiene como consecuencia la segregación de ésta del ámbito del pensamiento. La exploración literaria y artística, sin embargo, posibilitan cuestionar la pretensión de autodefinición de la razón, así como el lugar de la locura en el pensamiento y la cultura.

- El Cogito cartesiano, sin embargo, puede interpretarse como el intento de reflexión radical del pensamiento en el que no sólo se afianza la razón, sino que se reconoce a sí mismo en diversas formas de locura, como excesos que de hecho lo constituyen.

- Tal exceso, que el Cogito registra en sí mismo, es la huella del ingreso del sujeto al orden simbólico, como forma de violencia que lo desnaturaliza pero que también le posibilita desarrollarse en mundos socio-culturales virtuales, a través de internalizaciones que generan hábitos y costumbres al universalizar y volver necesario lo que en la experiencia del sujeto fue, en un primer momento, particular y contingente.

- Finalmente, la locura puede ser reinterpretada, no sólo como lo excluido por la razón, sino como la falta de reconocimiento de la virtualidad del orden

\footnotetext{
${ }^{47}$ Ibidem.
} 
simbólico, con lo que la misma razón, al perder de vista su carácter simbólico y asumirse como una expresión de lo real en sí, se vuelve loca. Como Chesterton afirmaba, el loco es el que cree que la realidad puede reducirse a lo que razona de ella.

- La validez de la mediación dependerá, en consecuencia, no de principios axiomáticos o de su correspondencia con la realidad exterior, sino de una lucha por la hegemonía, en la que está en juego la validez de hábitos y costumbres como formas de identidad en contextos socio-culturales de naturaleza simbólica.

\section{La lucha de Artaud}

Antonin Artaud es una referencia cotidiana cuando se aborda la relación entre el arte y la locura. Pero, ¿qué se entiende cuando se afirma que Artaud era un "loco"? ¿Y qué relación tiene ese calificativo con su arte y su pensamiento? Como posible acercamiento, propongo analizar aquí el viaje que realizó a México a partir de los textos que fue produciendo, lo cual nos permitirá acercarnos a las motivaciones que determinan su arte y su postura ante la realidad de su época. Por otro lado, estos textos son pertinentes para nuestro tema porque en ellos cuestiona radicalmente los límites de la racionalidad europea, en la búsqueda de una forma de pensamiento que dé cuenta de lo que él supone que fue excluido en occidente y que pretendía encontrar y experimentar en la antigua cultura mexicana. ${ }^{48}$

En enero de 1936, decepcionado por el desarrollo de la civilización europea, Artaud decidió embarcarse rumbo a México, motivado por la idea de encontrar los principios vivos de una auténtica cultura, bajo la creencia de que la revolución de 1910 había permitido resucitar las formas fundamentales de la civilización prehispánica. ¿Cuál es el sentido su búsqueda? ¿Qué encontró ahí? ${ }^{49}$

En "La palabra soplada", Derrida señala que Artaud buscaba realizar, a través del teatro, una creación pura que no se separe del cuerpo ni permanezca en un signo, obra $u$

\footnotetext{
${ }^{48}$ Para una visión amplia del pensamiento de Artaud, más allá de su actividad artística, consúltese Wilson Coêlho Pinto, “Antonin Artaud: ¿Tratamento cruel ou cirugía ontológica?", Utopía y Praxis Latinoamericana, 7, núm. 18 (septiembre, 2002): 69-79.

${ }^{49} \mathrm{Al}$ respecto, consúltese el intento de conceptualizar el viaje de Artaud a México - lo cual coincide con nuestras intenciones - de Johan Camilo Sánchez-Medina, "Cuerpo y escritura: Artaud y la experiencia Tarahumara”, Cuestiones de Filosofía, núm. 17 (2015): 193-208, doi.org/10.19053/01235095.4296.
} 
objeto. Derrida califica esta empresa como un intento de destruir la metafísica occidental ${ }^{50}$ basada en la dualidad de cuerpo-alma y palabra-existencia - porque tiende a establecer las normas de validez de las obras independientemente del cuerpo, los gestos y las experiencias del individuo, como si fuera una palabra soplada, inducida, impuesta o inspirada al autor, director y ejecutantes, desde el exterior. Como si fuera una orden, proferida desde un lugar ajeno a ellos, que tienen que obedecer. De esta manera, Derrida muestra que dicha palabra es una de las preocupaciones principales de Artaud. Constantemente refiere que le fue robada, sustraída; que se volvió ajena a él y que lo oprime en la forma de un mandato, que identifica en el desarrollo de la civilización europea. ${ }^{51}$ Europa, en consecuencia, se le presenta a Artaud como un orden que debe ser derrocado y como una palabra que debe ser recuperada, para recobrar su lugar en el cuerpo y sus experiencias. ${ }^{52}$

Según Derrida, Artaud pretendía abrir el mundo al "peligro" abrigo del orden que impone la metafísica, lo cual implica la formación de otro modo de consciencia; una que es consciente de lo que la determina como una potencia exterior y que se atreve a actuar más allá de los designios del orden; una que se opone a la separación de cuerpo, acción, pensamiento y palabra; a que el discurso sea la repetición de un texto que lo precede y determina. Por ello, Derrida nota que para Artaud hay dos tipos de inspiración, una buena y una mala: ${ }^{54}$ en la mala sólo se repite lo que el orden ha establecido; la buena viene de la vida misma y no se deja dictar por referencias externas. Lo importante, pues, es reencontrar la comunicación con uno mismo, ${ }^{55}$ al grado de plantearse la realización del momento mítico de una "vida sin diferencia". 56

\footnotetext{
${ }^{50}$ Derrida, "La palabra soplada", en La escritura y la diferencia, 219.

${ }^{51}$ Ibid., 220.

${ }^{52}$ Más adelante en el capítulo "El teatro de la crueldad y la clausura de la representación”, Derrida explica cómo esta empresa significó para Artaud un esfuerzo de eliminar de su pensamiento y lenguaje toda forma de representación, entendida como creación a partir de un original. En términos filosóficos, esto coincide con la propuesta de Deleuze y Guattari, desarrollada en El Anti Edipo. Capitalismo y esquizofrenia (Barcelona: Paidós, 1985) (Véase nota 2). Para profundizar en las implicaciones metafísicas de esta empresa, consúltese: Javier Agüero Águila, "Creación y crueldad: Artaud y la anti-génesis". Instantes y Azares. Escrituras Nietzscheanas, núm. 14 (otoño, 2014): 91-104.

${ }^{53}$ Derrida, "La palabra soplada", 221.

${ }^{54}$ Ibid., 224-225.

55 Para una lectura del pensamiento de Artaud, como una narrativa de sí, consúltese Sophie-Jan Arrien, "Ipséité et passivité: le montage narrative du soi (Paul Ricœur, Wilhelm Schapp et Antonin Artaud)". Laval Théologique et Philosophique, 63, núm. 3 (2007): 445-458. doi.org/10.7202/018171ar.

${ }^{56}$ Derrida, "La palabra soplada", 226.
} 
La cuestión, por supuesto, es que ese momento en que uno se encuentra más allá de toda dualidad y diferencia, es algo que no existe como tal y que, más bien, se ha de realizar artísticamente. ${ }^{57}$ Artaud buscó fuera de la metafísica europea en diversos sitios como el teatro balinés, la cosmogonía hindú, iraní, china y egipcia, y en la antigua cultura de México, investigando diversos modelos de representación, siempre en relación con el cuerpo, en distintas manifestaciones plásticas, rituales, dancísticas y hasta en sistemas de escritura, como los jeroglíficos y los códices prehispánicos.

En el marco de esta búsqueda es donde hemos de analizar el viaje de Artaud a México, país que particularmente le interesaba por la singular relación que en él se da entre la cultura prehispánica y la europea. De hecho, uno de sus proyectos del teatro de la crueldad, jamás realizado, era una puesta en escena de título La conquista de México, ${ }^{58}$ en la que planeaba exponer, además de la violencia de la colonización europea, la complejidad de las representaciones producidas a partir del choque entre lo católico y lo pagano, en un intento de mostrar que la imposición de un orden no cancela aquello sobre lo que se impone, pues esto se mantiene latente, siempre pugnando por reencontrar su lugar en el mundo, por descolonizarse, lo cual a los ojos de Artaud es equivalente a su propia búsqueda. $^{59}$

Al respecto, planteemos las mismas preguntas que Derrida:

el teatro, descolonizado de esa manera, ¿no sucumbirá bajo su propia crueldad? ¿Podrá resistir a su propio peligro? Liberado de la dicción, sustraído a la dictadura del texto, ¿no quedaría el ateísmo teatral entregado a la anarquía improvisadora y a la inspiración caprichosa del actor? ¿No se está preparando así otro sometimiento? ¿Otra sustracción del lenguaje hacia lo arbitrario y la irresponsabilidad $?^{60}$

El nuevo lenguaje corporal que intentó desarrollar Artaud — su atletismo afectivo, su entrenamiento de órganos, su disciplina gestual, su escritura jeroglífica encarnada, su

\footnotetext{
${ }^{57}$ Para tener una visión general de lo que podría considerarse la estética de Artaud, consúltese Charlotte Moore, "The Aesthetics of Antonin Artaud". Kinesis. Graduate Journal of Philosophy, 35, núm. 1 (primavera, 2008): 43-60.

${ }^{58}$ Antonin Artaud, "The Theater of Cruelty (Second Manifesto)", en The Theater and Its Double (New York: Grove Press, 1958), 126.

${ }^{59}$ A esta empresa le podemos oponer la crítica de Žižek sobre la ilusión poscolonial de un origen perdido que debe ser recuperado. Consúltese el tercer capítulo de la primera parte de Contragolpe absoluto, de título "La herida", y en particular los apartados titulados "La caída" y "El contragolpe anticolonial".

${ }^{60}$ Derrida, "La palabra soplada", 239.
} 
puesta en escena de las leyes que rigen los sueños_, ${ }^{61}$ ¿no terminará por instaurar una nueva metafísica, quizá más represora que la que busca eliminar? Su revuelta contra la civilización occidental, como indica Derrida, nos coloca en el límite entre el orden y la locura, entre la civilización y aquello que mantiene al margen. ${ }^{62}$ ¿No implica, entonces, su intento de revitalizar el lenguaje, el riesgo de caer en la incoherencia, el desorden, el delirio y, en general, la desarticulación lingüística? ${ }^{63}$

Para Artaud, este riesgo debe correrse porque más allá de la seguridad que puede brindar una civilización, le permitiría mantenerse viva, despierta y vinculada a la verdad. Lo contrario, la seguridad del seguimiento de normas, equivale a una forma de barbarie, al fracaso de la civilización. De hecho, Artaud refiere que uno de sus motivos para viajar a México es "huir de la barbarie" 64 que detectaba en Europa, la cual identificaba en tendencias como el imperialismo utilitario, el progreso material y mecánico, y el marxismo como ideología política, que se desarrollaban a costa del crecimiento interior.

El surrealismo, movimiento al cual se vinculó, fue una de las reacciones contra el progreso sin sentido que acontecía en Europa. Pero su problema, según Artaud, es que nació en "los bancos de la escuela". ${ }^{65}$ Se trataba de una revuelta moral contra la coerción del "Padre" en sus diversas manifestaciones, como la "Patria" o el "Patrón"; 66 contra la "violencia que la manía de aclarar las cosas ha terminado por llamar desmoralización". 67

Su problema, piensa Artaud, es que al ser un movimiento especulativo, se condenó a recaer en las formas de la metafísica contra la que se rebelaba.

El marxismo, como su expresión política, es otro ejemplo. Para Artaud, lejos de revitalizar nuestra capacidad de discurso, su ideología es "una mística escondida. Un ocultismo [...] se ha expresado alegóricamente y por larvas que han tomado el aire de

\footnotetext{
${ }^{61}$ El capítulo XII de El teatro y su doble está dedicado a estos temas.

${ }^{62}$ Derrida, "La palabra soplada", 244.

63 Para una crítica a este acercamiento de Derrida a la obra de Artaud, demasiado centrado, quizá, en la estructura trascendental del lenguaje, consúltese: Alejandro Vallega, "Thought's Obsesive Vigilance: At the Limit of Derrida's Reading of Antonin Artaud", Epoché. A Journal of History of Philosophy, 14, núm. 1 (otoño, 2009), 143-166.

64 Antonin Artaud, "Une civilisation”, en Euvres complètes VIII (París: Gallimard, 1956), 157. Las citas son traducidas al español del original en francés por el autor del artículo.

${ }^{65}$ Artaud, "Surréalisme et révolution", en Euvres complètes VIII, 171.

${ }^{66}$ Ibid., 171-172.

${ }^{67}$ Ibid., 174
} 
poesía". ${ }^{68}$ Por ello, tanto el marxismo como el surrealismo terminaron siendo tendencias de oposición meramente destructivas. Su idea era "quebrar lo real, engañar a los sentidos, desmoralizar de ser posible las apariencias, pero siempre con una noción de lo concreto". 69

Artaud pensaba que, en lugar de oponerse al Padre, uno más bien debía buscar reconciliarse Él. ${ }^{70}$ Comprender el orden en que uno vino a este mundo, como una especie de destino, e intentar aprender su lenguaje hasta hacerlo parte de uno mismo, como un órgano. En este sentido, Artaud no renunció a la revolución, pero sí a que ésta dependiera de una organización política como los partidos. ${ }^{71}$ La revolución debía aspirar a una realidad superior y subvertir las condiciones materiales, no a organizar lo material a través de una metafísica, tal como a su parecer hacía el marxismo.

La Revolución mexicana llamó la atención de Artaud porque en ella veía la posibilidad de superar los ídolos de la modernidad europea y revivir los mitos de la cultura prehispánica, a pesar de las tendencias marxistas de los intelectuales involucrados, como Diego Rivera. ${ }^{72}$ En específico, Artaud buscaba "un eco, o más bien una fuente, una verdadera fuente física de esta fuerza revolucionaria"; ${ }^{73}$ la fuerza que la movía y que Artaud suponía que estaba arraigada en su antigua cultura: "En una palabra, se cree que la Revolución mexicana es una revolución del alma indígena, una revolución para conquistar el alma indígena tal como era antes de Cortés". ${ }^{74}$

Artaud esperaba encontrar en México un nuevo concepto de hombre; uno que estuviera auténticamente ligado a las tradiciones ancestrales de su tierra, su raza, sus ritos y costumbres. Para él, era como si la revolución hubiera hecho "surgir el inconsciente olvidado de la raza", 75 el cual esperaba encontrar en sus manifestaciones culturales, incluso a pesar de

\footnotetext{
${ }^{68}$ Ibid., 173.

${ }^{69}$ Ibid., 175.

${ }^{70}$ Ibid., 178. ¿Cómo entender entonces su proclama en su poema "Para terminar con el juicio de Dios”? El Dios aquí referido tendría que ver más con la imposición de una palabra exterior - frecuentemente simbolizada por Artaud con la figura del crucificado-, que con el encuentro de la auténtica palabra. Podríamos hablar de un Dios falso y de otro verdadero.

${ }^{71}$ Ibidem. "¿A Artaud no le importa la revolución? Me preguntaron. No me importa la suya, no la mía, respondí al dejar el Surrealismo, porque el Surrealismo también se había convertido en un partido".

72 Artaud, "Un technicien du travail de la pierre: Monasterio", en Euvres complètes VIII, 299-300. "Sí, hay en los frescos de Diego Rivera un embrión de personalidad. Lo siento, pero ese embrión es todavía débil".

73 Artaud, "Premier contact avec la Révolution Mexicaine", en Euvres Complètes VIII, 238.

${ }^{74}$ Ibid., 239.

${ }^{75}$ Artaud, "Un technicien", 295.
} 


\section{enn-claves}

la apariencia occidental de las ciudades mexicanas, lo cual veía como una mera apropiación de la civilización europea. La pintora María Izquierdo fue su ejemplo favorito: "Sólo la pintura de María Izquierdo testifica de una inspiración verdaderamente indígena" ${ }^{76}$ Califica su obra de sincera, espontánea, primitiva e inquietante, más allá de ideologías o principios académicos. A su parecer, Izquierdo se sirve de las técnicas europeas "como si las quisiera anular". ${ }^{77}$ La diferencia entre Izquierdo y el surrealismo militante, es que su subversión de los principios de la técnica europea no era teórica, ni siquiera consciente: "Ella no desenreda claramente todo eso, sino que el espíritu de la raza habla tan fuerte en ella que incluso inconscientemente ella repite su voz". ${ }^{78}$ El espiritu de la raza habla en ella, no como una orden exterior, sino como una manifestación espontánea de sí misma, como una constante formación de sí y de su mundo: "Es eso lo que le da su carácter inquietante, único en toda la pintura mexicana; lleva el reflejo de un mundo en formación, de un mundo aún en fusión. Sus ruinas no evocan un mundo en ruinas, evocan un mundo reconstruyéndose". ${ }^{79}$

En Izquierdo se presenta lo que Artaud denomina una metafisica de la naturaleza, que se opone a las metafísicas teóricas, pues su pintura, sin planteárselo, regresa "todo lo que se ha querido retirar del mundo, y lo hace regresar sin alucinación". ${ }^{80}$ Permite, más que organizar políticamente a las personas y a los objetos, asimilar la cultura propia, sus formas de verdad; adaptarse al destino que imponen las condiciones propias de la tierra en la que se habita: "Cultivarse es comer su destino, asimilárselo por el conocimiento". ${ }^{81}$

Lo que a Artaud le importaba presenciar en México es cómo a partir de la revolución se intentaba recobrar el espíritu de su cultura, más allá de los proyectos político-sociales. La determinación teórica de la acción es justo el problema que detectaba en Europa, lo cual a su juicio implicaba un tipo de idolatría. En México, en cambio, presentía que se intentaba restablecer la comunicación con las fuerzas fundamentales de su cultura, cuyos orígenes se remontan al paganismo indígena. ${ }^{82}$

\footnotetext{
${ }^{76}$ Artaud, "La peinture de María Izquierdo", en Euvres complètes VIII, 301.

${ }_{78}^{77}$ Artaud, "Ce que je suis venu faire au Mexique", en in Euvres complètes VIII, 302.

${ }^{78}$ Ibidem.

${ }^{79}$ Ibid., 304.

${ }^{80}$ Artaud, "L'homme contre le destin", en Euvres complètes VIII, 187.

${ }^{81}$ Ibidem.

${ }^{82}$ Ibid., 186-189.
} 


\section{enn-claves}

$\mathrm{Su}$ viaje, pues, estaba motivado por la esperanza de encontrar las bases vivas de su cultura, sus fuentes primitivas de inspiración, sus mitos y rituales fundamentales, bajo la suposición de que, contrario a lo que sucedía en Europa, en México se mantenían vivos. ${ }^{83}$ ¿A qué se refiere por fuentes primitivas de inspiración de la cultura? ¿Y por qué supone que en México permanecían vivas?

Una cultura, supone, está viva cuando la verdad de sus mitos es realizada en prácticas cotidianas, es experimentada por cualquiera y no está reservada a una clase ni limitada a sus textos, obras u objetos. En Europa, piensa, no había ya mitos en los que la colectividad pudiera creer, sus dioses habían perdido contacto con la realidad, la noción de lo sagrado había desaparecido y la sociedad había caído en una idolatría de la razón, entendida como dominio de la naturaleza y organización de la materia. ${ }^{84}$ En México, en cambio, supone que, tras la revolución, los mitos y sus dioses estaban en vías de resucitar. ${ }^{85}$

Más específicamente, concibe dichos dioses como representaciones de las fuerzas que permiten la comunicación de lo interior en lo exterior, de la cosa en la palabra, del pensamiento y el acto, del espíritu y la materia. Son la representación de aquello que ha de hacer desaparecer la diferencia entre el discurso y el cuerpo; de lo que ha de permitir que la palabra se vuelva a manifestar físicamente y que el espíritu vuelva a vivificar la materia. ${ }^{86}$

Ahora bien, aunque se podría argumentar que en México hay una diversidad de culturas, cada una con sus costumbres, su lenguaje, sus dioses y su arte, Artaud sostiene que todas, en el fondo, son expresiones de una misma idea fundamental del hombre, de la naturaleza, de la vida y de la muerte ${ }^{87}$ que detrás hay una unidad, la cual pretendía descubrir y conocer. ${ }^{88}$ ¿Cómo intentó hacerlo?

Según Artaud, una cultura no se puede aprender a través de palabras o ideas, ${ }^{89}$ como si pudiera reducirse a información para transmitirse. "Ante la cultura de Europa que está escrita en textos y hace creer que la cultura está perdida si los textos son

\footnotetext{
${ }^{83}$ Artaud, "Une civilisation", en Euvres complètes VIII, 157-163.

${ }^{84}$ Ibid., 161-163.

${ }^{85}$ Ibid., 162.

${ }^{86}$ Ibid., 163.

${ }^{87}$ Artaud, "Lettre ouverte aux gouverneurs des États du Mexique", en Euvres complètes VIII, 232.

${ }^{88}$ Artaud, "L'homme contre le destin", en CEuvres complètes VIII, 194.

${ }^{89}$ Artaud, "Le Théâtre et les dieux", en CEuvres complètes VIII, 199.
} 


\section{enn-claves}

destruidos, yo digo que hay una cultura en la que se ha vivido en otros tiempos y que esta cultura perdida se basa en una idea materialista del espíritu". ${ }^{90}$ A esta idea materialista del espíritu, Artaud la llama "cultura orgánica": "una cultura basada en el espíritu en relación con los órganos, y el espíritu bañándose en todos los órganos, y respondiéndose al mismo tiempo". ${ }^{91}$ De esta forma, ser culto no implica necesariamente leer o escribir; no tiene que ver con tratar de adaptarse a las formas transmitidas en los textos, sino con entrenar los órganos del cuerpo para que éste se sostenga aun a pesar del cambio de normas, formas y patrones. ${ }^{92}$

Al respecto, Artaud especula sobre las diferencias entre el rol de la escritura en Europa y en México. Mientras en Europa se privilegian las formas abstractas, en los antiguos códices percibe la representación de dioses, los cuales "eran sobre todo Dioses en el espacio", ${ }^{93}$ como si "la Mitología de los Códices escondiera una ciencia del espacio con sus Dioses como agujeros sombríos, y sus sombras donde ruge la vida". ${ }^{94}$ Esta escritura funciona como una especie de representación teatral; una guía en la cual se tiene que interpretar la disposición espacial de los cuerpos y sus fuerzas de manera dinámica, lo cual invita al espíritu "a no petrificarse sobre sí mismo, sino al contrario, si podemos decirlo, a andar", ${ }^{95}$ a ejecutar movimientos más que a determinar una serie de ideas y argumentos sobre cómo se ha de ordenar el mundo.

Por ello, más que ideas, lo que en realidad le interesaba estudiar a Artaud de la cultura indígena eran sus ritos y danzas, como si fueran una posible forma de teatro, bajo el supuesto de que son manifestaciones directas de la fuerza de la tierra. De hecho, piensa que en la antigüedad la educación, más que basarse en la adquisición y manejo de cierta información a través de prácticas mnemotécnicas — como en la actualidad-, "era una convocación material de fuerzas y, si me atrevo a expresarme así, diré que a través de la educación uno frotaba el organismo humano para que las fuerzas afloraran en él". ${ }^{96}$

\footnotetext{
${ }^{90}$ Ibidem.

${ }^{91}$ Ibid., 201.

${ }^{92}$ Ibid., 202.

${ }^{93}$ Ibid., 204.

${ }^{94}$ Ibid., 204.

${ }^{95}$ Ibid., 205.

${ }^{96}$ Artaud, "Secrets éternels de la culture", en Euvres complètes VIII, 279. 


\section{(en-claves}

Bajo estos principios, la única forma en que Artaud realmente podía conocer la cultura mexicana era participando activamente en alguno de sus ritos. Y encontró la posibilidad en la ingesta de peyote, para lo cual dejó la Ciudad de México y se trasladó a la Sierra Tarahumara. El recuento de su experiencia es complicado por la densidad de la descripción y su carga simbólica. Sin embargo, hemos de destacar que, de acuerdo a su percepción, el rito permite a los tarahumaras distinguir con claridad los elementos en juego en su mente a través de un trabajo analítico de separación y distribución, que posibilita que la consciencia de su realidad aumente y que se consolide la unidad de la identidad; ${ }^{97}$ lo cual contrasta con la descripción que Artaud ofrece de su terapia de electrochoques en el asilo mental de Rodez, ${ }^{98}$ pues en ella más bien experimentó la disociación de los elementos que constituían su vida psíquica, lo cual tenía como consecuencia la pérdida de conciencia y de control, así como la imposibilidad de reconocerse.

Artaud da cuenta, a través de su experiencia con el peyote, de que las bases vivas de la cultura tienen que ver con aprender a relacionarse con la naturaleza del entorno en el que se vive, más que con asumir principios o con aplicar teorías. En este sentido, hemos de concluir que el viaje a México le permitió hallar una nueva forma de relacionarse consigo mismo, más que la posibilidad de determinar principios para el teatro o formas de organización. Pasó por una vivencia que no puede ser comunicada de manera objetiva en algún tipo de formalización, por lo que, para tratar de comprenderla, tendríamos que vivir una experiencia semejante.

En último término, el descubrimiento de Artaud no es algo que se pueda mostrar en una obra, exponer en un texto o presentar como un objeto, sino que consiste en la posibilidad de trascender los límites impuestos por los desarrollos de la civilización que nos mantienen alienados y nos impiden tener control de nosotros mismos. Más que encontrar un mundo nuevo en México, su viaje le permitió "salir de un mundo falso". 99

\footnotetext{
${ }^{97}$ Antonin Artaud, "Le rite du peyotl chez les Tarahumaras", en Euvres complètes IX (París: Gallimard, 1956), 20.

${ }^{98}$ Ibid., 38.

99 Antonin Artaud, "Y es en México...", en México y Viaje al país de los Tarahumaras (México: Fondo de Cultura Económica, 1984), 342.
} 


\section{(en-claves}

\section{Conclusiones}

Sin duda, Artaud comprendía la violencia de la imposición del orden simbólico y los efectos alienantes que tenían sobre su vida e identidad, constituyendo su subjetividad como una palabra ajena, robada. En función de ello, quizá lo más interesante de su obra y pensamiento es que a partir de este motivo emprendió una búsqueda y una lucha, tratando de recuperar esa palabra, para integrarla a su cuerpo y hacerla vivir.

Ahora bien, justo esta pretensión es lo que Žižek define como locura, porque implica la falta de reconocimiento del carácter simbólico de la palabra así como la suposición de una presencia originaria que puede ser encontrada más allá del texto —en términos de Derrida- ${ }^{100}$ ¿No es entonces la creencia sincera en una metafísica de la presencia - o como Artaud la denominó, una metafísica de la naturaleza, una cultura orgánica, una concepción materialista del espíritu, el cuerpo más allá de su representación-, un signo de locura no reconocida, que acompaña al pensamiento de Artaud como una especie de suplemento que, más allá de los criterios de la razón, impulsa su lucha, su búsqueda, su creatividad y el sentido mismo de su existencia?

El caso de Artaud es relevante porque éste no acepta el predominio de la razón ni se conforma con la alienación del modo de vida occidental. Lo cual no lo convierte en un ser irracional, sino que le permite trazar, de manera análoga a Foucault, que es la razón - como producto específico de la cultura europea - lo que lo ha segregado y recluido en instituciones mentales y lo que obstaculiza su productividad y existencia plena. En este sentido, como identificó Foucault, el arte y pensamiento de Artaud pudieron adquirir valor al cuestionar los límites de su identidad y cultura, lo cual a su vez le permitió aventurarse en la exploración de nuevas posibilidades en el reconocimiento de otras fuentes de cultura.

Con ello, aunque tal vez resulte aventurado clasificar a Artaud como figura del pensamiento descolonizador, podemos asegurar que lo es de un pensamiento que se rebela a la hegemonía occidental — a la que aplica una crítica de la perversión de su

\footnotetext{
${ }^{100}$ Todo esto, como mencionamos en la nota 52, está implicado en el rechazo de Artaud a la noción de representación.
} 


\section{enn-claves}

racionalidad - y que intenta además descubrir y producir una cultura que se ajuste de mejor manera a su propia experiencia.

Lo que aquí hemos de cuestionar del proyecto de Artaud, como parte de una reflexión acerca de las luchas por la hegemonía en nuestros tiempos, tal como hacen Derrida y Žižek, es si su pensamiento es lo suficientemente consciente, reflexivo y radical como para comprender, dentro del orden del lenguaje, la auténtica naturaleza de su lucha. ¿Basta con que Artaud reconociera que su locura es el producto de la imposición de una forma histórica de racionalidad, producto del desarrollo de la técnica y modo de vida occidental, contra la que luchó, supuestamente liberándose de ella en México, gracias a su participación en el rito de ingesta de peyote? ¿No es además necesario — como hizo Descartes, según Derrida - reconocer que la locura no es simplemente un fenómeno de exclusión histórico y cultural, sino un momento fundante en el desarrollo de la subjetividad que — como apunta Žižek — nos introduce al orden simbólico, posibilitando de hecho nuestra identidad y los conflictos que la definen? Es decir, ¿no le faltó reconocer a Artaud que la alienación contra la que luchaba y de la cual intentó liberarse es de hecho lo que lo define como sujeto y lo que le permite tener una identidad como parte de un orden simbólico, el cual, por ello, no es sólo un horizonte cultural, sino trascendental?

Esta cuestión es de máxima relevancia en una época como la nuestra en que las luchas por la hegemonía cultural, de tono identitario, parecen dominar la opinión pública. Es ya un lugar común que los llamados estudios culturales, el posestructuralismo e incluso la teoría crítica, centren sus esfuerzos en la denuncia de la imposición de la racionalidad de una forma cultural que ha reprimido una serie de identidades, apoyando su lucha por liberarse y afirmarse, con la dilucidación de cómo se operó la imposición y con el diseño de estrategias para combatirla. En este sentido, las estrategias de Artaud podrían considerarse precursoras de las tendencias del actual panorama cultural, tal como señala Foucault. ${ }^{101}$

¿No es sintomático, no obstante, que la lucha de Artaud —como sucede con las actuales - se realice en el ámbito de la cultura, de la representación estética y de la

\footnotetext{
${ }^{101}$ Para ampliar esta idea, consúltese: Jonathan Piedra Alegría, "Re-presentando a la vida: Artaud y la posmodernidad". Praxis. Revista de Filosofia, núm. 71 (junio-diciembre, 2013): 119-139, doi.org/10.15359/praxis.71.5.
} 
experiencia individual, y no en el de la política organizada, al grado de rechazar explícitamente al marxismo y los partidos políticos como formas de imposición de la racionalidad occidental ${ }^{102}$ ¿No deberíamos reconocer en ello la manifestación de una metafísica de la presencia, como indica Derrida, o el gesto de una inadvertida imposición ideológica, como señalaría Žižek? ${ }^{103}$

Ciertamente, con Foucault, hemos de reconocer que existe, histórica y culturalmente, el fenómeno de la imposición violenta de formas discursivas como criterios universales de racionalidad, que llevan la marca de la colonización occidental, no sólo sobre otras culturas, sino sobre cualquier identidad que no se adapte a su dinámica tecno-científico-económica. Que ello, a su vez, pone las condiciones de una lucha por la hegemonía en la que está en juego la autonomía e identidad de los individuos involucrados. Sin embargo, ¿la clave de la lucha está en el reconocimiento y actualización de una identidad más allá de la imposición de la razón, como si se tratara de hacer valer la locura que fue segregada y recluida?

Para finalizar, planteemos la siguiente cuestión incómoda: ¿no fue justo el intento de revivir su identidad cultural profunda, accesible sólo a quienes podían experimentarla en su cuerpo, más allá de los límites de la racionalidad occidental, lo que caracterizó la empresa nazi? Artaud rechazaría esta interpretación, pues los nazis a sus ojos no serían más que un ejemplo, junto con el comunismo, del fracaso de la racionalidad instrumental de Occidente, que rechaza la presencia espiritual en el cuerpo de la identidad en que se encuentran las raíces de la verdadera cultura. ${ }^{104}$ Pero, siguiendo a Derrida y a Žižek, tal vez la postura de Artaud es el gesto ideológico por excelencia que impide reconocer que la lucha por la hegemonía no radica en la

\footnotetext{
${ }^{102}$ Consúltese, por ejemplo, la reseña de Žižek, "Badiou pense à tout”, sobre la publicación en Francia de Lógicas de los mundos de Badiou. Ahí, Žižek celebra la audacia de Badiou de defender la posición de universalidad frente a la defensa de los particularismos y su crítica a lo que éste denomina materialismo democrático.

${ }^{103}$ Véase Slavoj Žižek, "Multiculturalismo, o la lógica cultural del capitalismo multinacional". En Fredric Jameson y Slavoj Žižek (Eds.), Estudios culturales. Reflexiones sobre el multiculturalismo (Buenos Aires: Paidós, 1998).

${ }^{104}$ En Heliogábalo o el anarquista coronado, encontramos otro ejemplo de lo que para Artaud sería una auténtica afirmación de la voluntad más allá de las leyes de la política institucionalizada, a través de una serie de prácticas que tienen su base en el propio cuerpo e identidad sexual del emperador, bajo la influencia de la cosmovisión siria. ¿No corre, sin embargo, esta representación de la autoafirmación de la voluntad auténtica, el peligro de justificar prácticas políticas fascistas en nombre de una identidad profunda, aunque no sea reconocida públicamente?
} 


\section{enn-claves}

recuperación de la presencia, el cuerpo, la identidad cultural o la experiencia profunda, sino que se define en la estructura del orden simbólico, en función de sus antagonismos irresolubles, por lo que más bien requiere de formas de organización política, en el marco de una estricta discusión teórica que, así como los nazis confundieron la lucha de clases con la lucha racial, Artaud la confundió con la lucha por la identidad cultural y la búsqueda espiritual. Y que tal vez, en nuestros tiempos, la lucha de clases se sigue confundiendo con una por la identidad cultural, espiritual, racial y de género, porque no se reconocen adecuadamente sus componentes político-económicos. 


\section{(en-claves}

\section{Bibliografía}

Agüero Águila, Javier. "Creación y crueldad: Artaud y la anti-génesis". Instantes y Azares. Escrituras Nietzscheanas, núm. 14 (otoño, 2014): 91-104.

Arrien, Sophie-Jan. "Ipséité et passivité: le montage narrative du soi (Paul Ricœur, Wilhelm Schapp et Antonin Artaud)". Laval Théologique et Philosophique, 63, núm. 3 (2007): 445-458. https://doi.org/10.7202/018171ar.

Artaud, Antonin. Heliogabalo o el anarquista coronado. Buenos Aires: Argonauta, 2006.

Artaud, Antonin. México y Viaje al país de los Tarahumaras. México: Fondo de Cultura Económica, 1984.

Artaud, Antonin. Euvres complètes IX. París: Gallimard, 1956.

Artaud, Antonin. Euvres complètes VIII. París: Gallimard, 1956.

Artaud, Antonin. Para terminar con el juicio de Dios y otros poemas. Buenos Aires: Caldén, 1975.

Artaud, Antonin. The Theater and Its Double. New York: Grove Press, 1958.

Bouillon, Anne. Gilles Deleuze et Antonin Artaud. L'impossibilité de penser. París: L'Harmmattan, 2016.

Cavallazzi, Alejandro. “¿Qué es antifilosofía? Una consideración según Lacan, Badiou y la filosofía edificante de Rorty". Revista interdisciplinaria de Filosofía y $\begin{array}{llll}\text { Psicología, } & \text { 14, núm. } & 2 & \text { (2019). }\end{array}$ https://www.revistalimite.cl/index.php/limite/article/view/108/109.

Cealey Harrison, Wendy. "Madness and Historicity: Foucault and Derrida, Artaud and Descartes". History of the Human Sciences, 20, núm. 4 (2007): 79-105. https://doi.org/10.1177/0952695107082492.

Chesterton, G. K. Ortodoxia. México: Porrúa, 1998.

Coêlho Pinto, Wilson. "Tratamento cruel ou cirugía ontológica". Utopía y Praxis Latinoamericana, 7, núm. 18 (septiembre, 2002): 69-79.

Deleuze, Gilles. Francis Bacon. La logique de la sensation. París: Editions de la Différence, 1981.

Deleuze, Gilles, y Félix Guattari. “CCómo hacerse un cuerpo sin órganos?”. En Mil mesetas. Capitalismo y esquizofrenia. Valencia: Pre-Textos, 2002. 


\section{enn-claves}

Deleuze, Gilles, y Félix Guattari. El Anti Edipo. Capitalismo y esquizofrenia. Barcelona: Paidós, 1985.

Derrida, Jacques. La escritura y la diferencia. Barcelona: Anthropos Editorial, 2012.

Derrida, Jacques. De la gramatología. México: Siglo XXI, 1986.

Descartes, René. Meditaciones metafísicas. Barcelona: Espasa, 2015.

Dumoulié, Camille. Nietzsche y Artaud. Por una ética de la crueldad. México: Siglo XXI, 1996.

Foucault Michel, y Deleuze, Gilles. "Los intelectuales y el poder", en Microfisica del poder. Madrid: Las ediciones de la Piqueta, 1980.

Foucault, Michel. El gobierno de sí y de los otros. México: Fondo de Cultura Económica, 2009.

Foucault, Michel. Historia de la locura en la época clásica II. México: Fondo de Cultura Económica, 1976.

Freud, Sigmund. "Lo ominoso". En Obras completas. Volumen XVII. Buenos Aires: Amorrortu, 1992.

Kant, Immanuel. Crítica de la razón pura. Madrid: Tecnos, 2011.

Kant, Immanuel. Fundamentación de la metafísica de las costumbres. Madrid: Ediciones Encuentro, 2033.

Kristeva, Julia. "Le sujet en procès". En Polylogue. París: Seuil, 1977.

Lacan, Jacques. Seminario 10. La angustia. Buenos Aires: Paidós, 2006.

López, Paola Andrea. "El heroísmo de Antonin Artaud". Praxis Filosófica, núm. 49 (juliodiciembre 2019): 151-170. https://doi.org/10.25100/pfilosofica.v0i49.8246.

Moore, Charlotte. "The Aesthetics of Antonin Artaud". Kinesis. Graduate Journal of Philosophy, 35, núm. 1 (primavera, 2008): 43-60.

Piedra Alegría, Jonathan. "Re-presentando a la vida: Artaud y la posmodernidad". Praxis. Revista de Filosofia, núm. 71 (junio-diciembre, 2013): 119-139. https://doi.org/10.15359/praxis.71.5.

Poe, Edgar Allan. Filosofía de la composición. México: El Colegio Nacional, 2011.

Sánchez-Medina, Johan Camilo. "Cuerpo y escritura: Artaud y la experiencia Tarahumara". Cuestiones de Filosofía, núm. 17 (2015): 193-208. doi.org/10.19053/01235095.4296. 


\section{enn-claves}

Shaw, Jon K. "The Life of an Idiot: Artaud and the Dogmatic Image of Thought after

Deleuze". Theory, Culture \& Society, núm. 33 (2016): 233-252. https://doi.org/10.1177/0263276416650723.

Vallega, Alejandro. “Thought's Obsesive Vigilance: At the Limit of Derrida's Reading of Antonin Artaud". Epoché. A Journal of History of Philosophy, 14, núm. 1 (otoño, 2009), 143-166.

Žižek, Slavoj. "Multiculturalismo, o la lógica cultural del capitalismo multinacional". En Fredric Jameson y Slavoj Žižek (Eds.), Estudios culturales. Reflexiones sobre el multiculturalismo. Buenos Aires: Paidós, 1998.

Žižek, Slavoj. "Badiou pense à tout". Libération, 22 de marzo, 2007. https://next.liberation.fr/livres/2007/03/22/badiou-pense-a-tout_88141.

Žižek, Slavoj. Menos que nada. Hegel y la sombra del materialismo dialéctico. Madrid: Akal, 2015.

Žižek, Slavoj. Contragolpe absoluto. Para una refundación del materialismo dialéctico. Madrid: Akal, 2016. 